\title{
Beetroot juice and exercise performance
}

\author{
This article was published in the following Dove Press journal: \\ Nutrition and Dietary Supplements \\ 7 November 2013 \\ Number of times this article has been viewed
}

\author{
Michael J Ormsbee' \\ Jon Lox' \\ Paul J Arciero ${ }^{2}$ \\ 'Department of Nutrition, Food, \\ and Exercise Sciences, Human \\ Performance Lab, Florida State \\ University, Tallahassee, FL, USA; \\ ${ }^{2}$ Department of Health and Exercise \\ Sciences, Human Nutrition and \\ Metabolism Lab, Skidmore College, \\ Saratoga Springs, NY, USA
}

\begin{abstract}
Increased sales and consumption of organic and natural foods reflect consumers heightened interest in promoting health and improving athletic performance. Of these products, beetroot and its constituents have become increasingly popular in the arena of exercise performance, mainly due to the high concentrations of nitrate. Studies have indicated beetroot juice (BRJ) may improve exercise time to exhaustion, running performance, and increase muscular efficiency during moderate intensity exercise. The purpose of this review is to examine the efficacy of BRJ to serve as an ergogenic aid in athletic performance. It appears that BRJ may provide modest performance enhancement; however, more research is needed to clearly identify mechanisms of action and proper dosing patterns to maximize the performance benefits of BRJ.
\end{abstract}

Keywords: beetroot, nitrate, betaine, sports nutrition

\section{Introduction}

In the world of athletic competition, margins of victory are becoming smaller, and in some cases may literally come down to a fraction of a second or the ability to contract a single motor unit one more time. Thus, athletes are constantly in pursuit of any advantage to improve athletic performance. Some athletes may turn toward nutritional supplements, from both natural and organic sources, to provide this edge. Not surprisingly, during the period from 1999 to 2009, the US market for organic and natural foods experienced an increase in annual growth rate from $22.5 \%$ to $31.1 \%$, whereas the supplement market had a decline in annual growth rate from $34.5 \%$ to 24.8\%. ${ }^{1}$ In addition, the forecast for "Estimated Compound Annual Sales Growth" from 2010 to 2017 is projected to be $5 \%$ for supplements compared to $8 \%$ for natural and organic foods. ${ }^{1}$ Given this trend for organic and natural food products, it is particularly relevant to understand whether there is an added performance benefit due to the ingredients within these food products acting additively, synergistically, or even negatively compared to a concentrated dose of the isolated bioactive ingredient from the whole food or product.

Currently, one of the more popular natural foods considered to help athletic performance is beetroot (Beta vulgaris), one of the most common varieties of beet in North America. Beetroot is an excellent source of antioxidants and micronutrients, including (in descending order by weight) potassium, betaine, sodium, magnesium, vitamin $\mathrm{C}$, and nitrate $\left(\mathrm{NO}_{3}{ }^{-}\right)$and contains $29 \mathrm{kcal}$ per $100 \mathrm{~g}^{2}$ The color of beetroot stems from its purple and yellow pigments (betacyanin and betaxanthin, respectively), known collectively as betalains. These betalains have 
potential antioxidant capabilities. ${ }^{3,4}$ Interestingly, BRJ has been marketed on the Internet to support digestive and blood health, improve energy, be a natural cleanser, and increase levels of nitric oxide (NO) leading to increased blood flow. In addition, BRJ has been indicated to possess anticancer properties, can lower the risk of coronary events (stroke and peripheral vascular disease), lower blood pressure, and reduce inflammation. ${ }^{5}$ These claims have boosted the popularity of BRJ.

Several of the properties of BRJ mentioned above have been hypothesized to enhance athletic performance. For example, betaine has been shown to favorably enhance performance outcomes. ${ }^{6}$ However, the additive or synergistic effects of the constituents contained within BRJ have not been extensively studied. Nevertheless, both anecdotal and scholarly evidence supports the use of BRJ to produce faster finish times, ${ }^{7,8}$ increase time to exhaustion, ${ }^{9-11}$ reduce steadystate oxygen $\left(\mathrm{O}_{2}\right)$ consumption, ${ }^{9,10}$ increase peak power, ${ }^{7,12}$ and increase work rate at the gas exchange threshold ${ }^{12}$ (see Table 1). Therefore, this review will examine the impact specifically of BRJ, rather than each constituent, on athletic performance.

\section{Beetroot, $\mathrm{NO}_{3}^{-}$, and $\mathrm{NO}$}

Beetroot has a high $\mathrm{NO}_{3}{ }^{-}$content $(>250 \mathrm{mg} / 100 \mathrm{~g}$ of fresh weight), among the highest assessed, and other foods high in $\mathrm{NO}_{3}{ }^{-}$include spinach, celery, lettuce, and carrot juice. ${ }^{13}$ $\mathrm{NO}_{3}{ }^{-}$can be reduced to nitrite via bacteria in the oral cavity and by specific enzymes (eg, xanthine oxidase) within tissues. There are several pathways to metabolize nitrite to NO and other biologically active nitrogen oxides. ${ }^{14}$ $\mathrm{NO}$ is a signaling molecule formed in the endothelium by the enzyme endothelium NO synthase, which triggers the vasculature to relax (vasodilatation) by interacting with vascular smooth muscle leading to increased blood flow. ${ }^{15,16}$ NO facilitates increased blood flow at rest ${ }^{17}$ and during exercise. ${ }^{18}$

Given these properties, NO has gained a lot of attention for possible exercise improvements including increased $\mathrm{O}_{2}$, glucose, and other nutrient uptake to better fuel working muscles. Bradley et al ${ }^{19}$ and Balon and Nadler ${ }^{20}$ reported NO production contributed significantly to exercise-induced skeletal muscle glucose uptake, independent of skeletal muscle blood flow. Currently there is no means to provide NO supplementation through the diet, as it is a gas, thus BRJ and its high $\mathrm{NO}_{3}^{-}$concentration is used as a means to generate $\mathrm{NO}$ endogenously. In fact, up until this point, much of the support for NO use to improve exercise performance has relied heavily on "borrowed science" using amino acids such as L-arginine. ${ }^{21}$ Much more impressive is the growing body of scientific data in support of whole food sources of inorganic $\mathrm{NO}_{3}^{-}$, such as that found in BRJ, and improved athletic performance.

\section{BRJ, dietary $\mathrm{NO}_{3}^{-}$, and exercise performance \\ Aerobic exercise}

Lansley et $\mathrm{al}^{9}$ examined whether the exercise performance benefits of BRJ were attributed to its high $\mathrm{NO}_{3}{ }^{-}$content or its other potentially bioactive compounds. Nine healthy, physically active men consumed either $0.5 \mathrm{~L}$ of BRJ ( $6.2 \mathrm{mmol} /$ day of $\mathrm{NO}_{3}^{-}$) or $0.5 \mathrm{~L}$ of $\mathrm{NO}_{3}^{-}$-depleted $\mathrm{BRJ}$ placebo $\left(0.0034 \mathrm{mmol} /\right.$ day of $\left.\mathrm{NO}_{3}^{-}\right)$for 6 days followed by acute bouts of submaximal and high-intensity (to exhaustion) running and incremental knee extension exercises. BRJ consumption increased plasma nitrite by $105 \%$ and reduced the $\mathrm{O}_{2}$ cost for constant-work-rate moderate and severe-intensity running by $\sim 7 \%$ compared to placebo. In addition, time to exhaustion was increased during severe-intensity running by $\sim 15 \%$ and incremental knee extension exercise by $\sim 5 \%$ with BRJ compared to placebo. ${ }^{9}$ These findings suggest that the performance benefit $\left(\mathrm{O}_{2}\right.$ sparing and enhanced exercise tolerance) of consuming BRJ is attributed to its high $\mathrm{NO}_{3}^{-}$ content. More recently, Murphy et $\mathrm{al}^{8}$, using a double-blind placebo-controlled crossover trial, had eleven recreationally fit men and women consume either baked beetroot (200 g with $\geq 500 \mathrm{mg} \mathrm{NO}_{3}^{-}$) or an isocaloric placebo (cranberry relish) 75 minutes prior to performing a $5 \mathrm{~km}$ time trial (TT) treadmill run to determine whether whole beetroot consumption would improve running performance. They observed a nonsignificant, 41 -second faster finishing time $(12.3 \pm 2.7$ versus $11.9 \pm 2.6 \mathrm{~km} /$ hour, respectively; $P=0.06$ ) following beetroot consumption compared to placebo. Interestingly, during the last 1.1 miles $(1.8 \mathrm{~km})$ of the $5 \mathrm{~km}$ run, running velocity was $5 \%$ faster $(12.7 \pm 3.0$ versus $12.1 \pm 2.8 \mathrm{~km} /$ hour, respectively; $P=0.02)$ and rating of perceived exertion was lower $(13.0 \pm 2.1$ versus $13.7 \pm 1.9$, respectively; $P=0.04)$ during the beetroot trial compared to the placebo. The authors suggest that nitrite levels may have continued to rise during the $5 \mathrm{~km}$ run, resulting in the late race benefits. Therefore, it appears that the ingestion of whole-foods containing inorganic $\mathrm{NO}_{3}^{-}$(such as beetroot or BRJ) increases plasma nitrite and ultimately NO levels, which favorably affect the cellular and vascular pathways, which likely result in the observed improvements in athletic performance. ${ }^{8}$ For a summary, see Table 1 . 


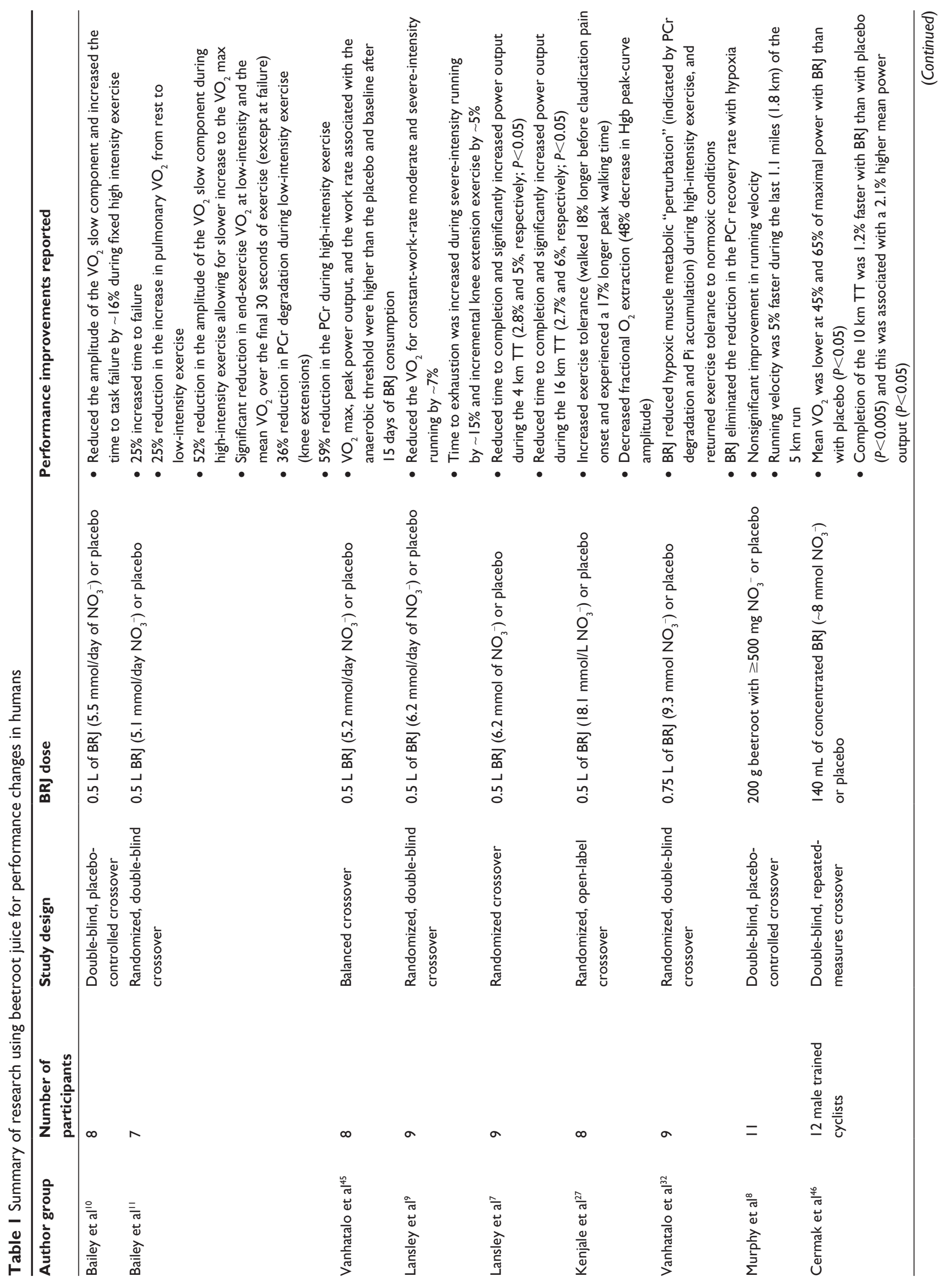




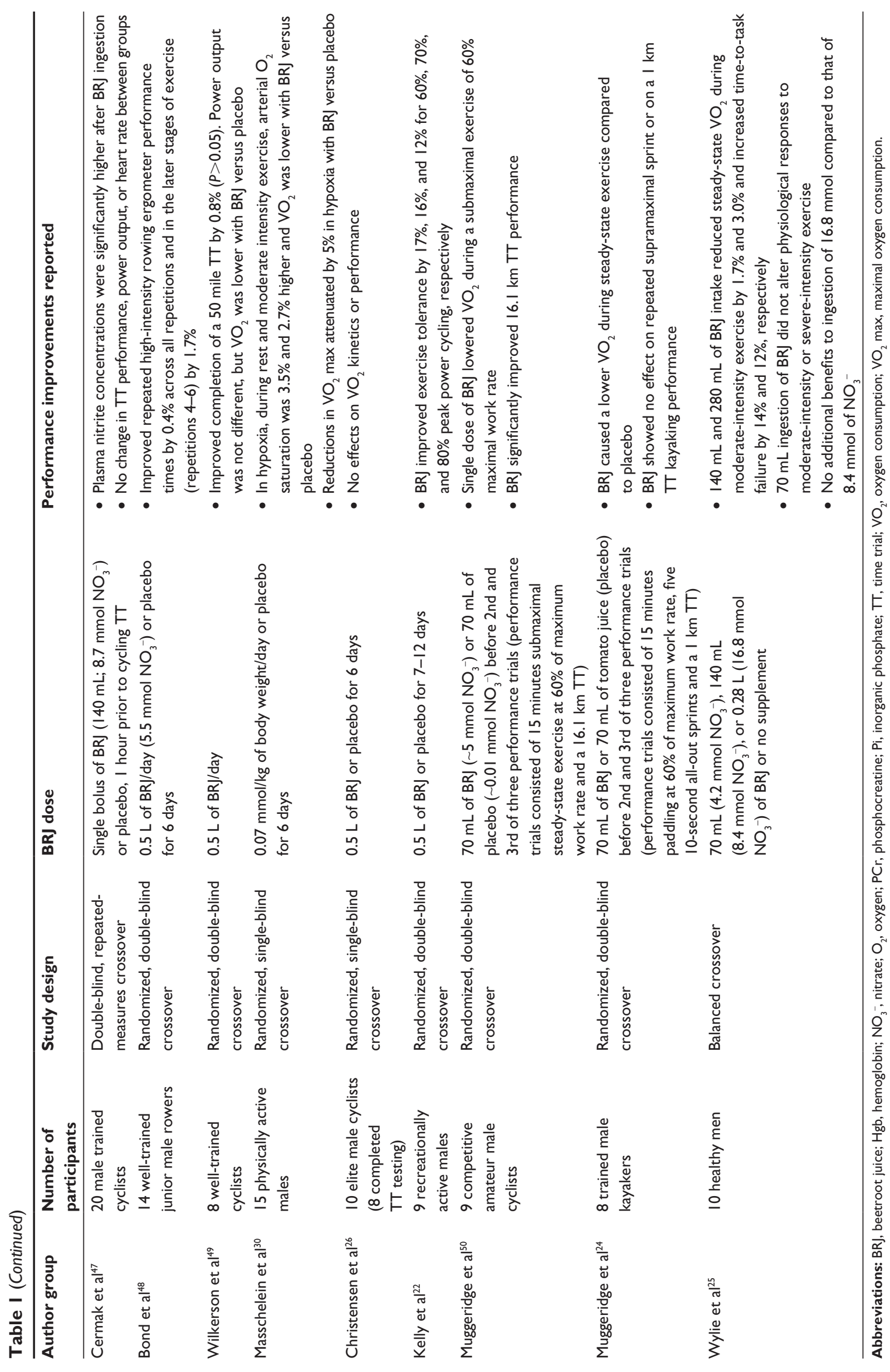




\section{Power output and performance}

Given the impact of BRJ on aerobic performance, it would seem likely that BRJ would also favorably impact other markers of athletic performance. The effects of BRJ ingestion on power output, oxygen consumption $\left(\mathrm{VO}_{2}\right)$, and cycling time trial (TT) performance was examined by Lansley et $\mathrm{al}^{7}$ using nine competitive male cyclists who consumed either $0.5 \mathrm{~L} \mathrm{BRJ}\left(6.2 \mathrm{mmol}\right.$ of $\left.\mathrm{NO}_{3}^{-}\right)$or placebo containing $\mathrm{NO}_{3}^{-}$-depleted $\mathrm{BRJ}\left(0.0047 \mathrm{mmol}\right.$ of $\left.\mathrm{NO}_{3}^{-}\right)$before each TT of $4 \mathrm{~km}$ or $16 \mathrm{~km}$. BRJ consumption increased plasma nitrite by $138 \%$ and resulted in significantly reduced time to completion and increased power output during both the $4 \mathrm{~km}(2.8 \%$ and 5\%, respectively; $P<0.05)$ and $16 \mathrm{~km}$ TTs $(2.7 \%$ and $6 \%$, respectively; $P<0.05)$ compared to the placebo treatment. ${ }^{7}$

Similarly, in a crossover study, Bailey et $a{ }^{10}$ supplemented eight healthy, recreationally active men with $0.5 \mathrm{~L}$ of BRJ $\left(5.5 \mathrm{mmol} /\right.$ day of $\left.\mathrm{NO}_{3}^{-}\right)$or a low-calorie blackcurrant juice cordial (negligible $\mathrm{NO}_{3}^{-}$content) for 6 days, and they performed moderate ( $80 \%$ gas exchange threshold) and intense cycling $(70 \%$ of the difference between the power output at the gas exchange threshold and $\mathrm{VO}_{2}$ peak) protocols during the last 3 days. BRJ ingestion increased the average plasma nitrite by $96 \%$ and reduced muscle deoxyhemoglobin amplitude by $13 \%$, suggesting that fractional $\mathrm{O}_{2}$ extraction was reduced. In addition, BRJ consumption reduced the amplitude of the $\mathrm{VO}_{2}$ slow component (defined as a delayed onset of $\mathrm{VO}_{2}$ consumption during high intensity exercise. Similar to the previous data reported, these authors concluded that increased dietary inorganic $\mathrm{NO}_{3}^{-}$consumption from $\mathrm{BRJ}$ has the potential to improve high-intensity exercise tolerance. ${ }^{10}$

While it appears that BRJ does improve exercise performance, the minimal time needed to use BRJ for a performance benefit remains to be elucidated. One attempt to answer these questions was reported by Vanhatalo et al. ${ }^{12}$ These authors examined the effects of acute ( 1 and 5 days) and chronic (15 days) BRJ consumption on a moderateintensity exercise bout ( $90 \%$ gas exchange threshold) and an incremental cycle ergometer ramp test (increasing work rate by $1 \mathrm{~W}$ every 2 seconds [ $30 \mathrm{~W} /$ minute]) to exhaustion. Eight healthy subjects (five males, three females) consumed either $0.5 \mathrm{~L} \mathrm{BRJ}\left(5.2 \mathrm{mmol} /\right.$ day $\left.\mathrm{NO}_{3}^{-}\right)$or a placebo (blackcurrant juice cordial with negligible $\mathrm{NO}_{3}{ }^{-}$content) for 15 days and were exercise tested on days 1, 5, and 15. Plasma nitrite was significantly increased on all test days following BRJ compared to placebo. The $\mathrm{O}_{2}$ cost of moderate-intensity exercise (increase in $\mathrm{VO}_{2}$ relative to the increase in external work rate) was lower during BRJ ingestion and was maintained throughout the 15 days ( $P=0.002$; effect size, 0.51). Maximal $\mathrm{O}_{2}$ consumption $\left(\mathrm{VO}_{2} \max \right)$, peak power output, and the work rate associated with the anaerobic threshold were all higher following 15 days of BRJ consumption compared to placebo and baseline conditions. In addition, systolic and diastolic blood pressures were reduced by $4 \mathrm{mmHg}$ ( $-3 \%$ and $-5 \%$, respectively). Compared with placebo, systolic blood pressure was significantly lower at 2.5 hours as well as at 2, 12, and 15 days post-ingestion of BRJ (95\% confidence interval -12.4 to $-1.1 ; P<0.05)$. The mean diastolic blood pressure was significantly different between groups $(P=0.003)$ and decreased with BRJ compared to placebo ( $95 \%$ confidence interval -4.3 to $-1.3 ; P<0.01)$. The authors concluded that acute ( $1-5$ days) dietary $\mathrm{NO}_{3}{ }^{-}$supplementation significantly decreased blood pressure and the $\mathrm{O}_{2}$ cost of submaximal exercise and increased $\mathrm{VO}_{2}$ max and peak power output, and these outcomes were maintained for at least 15 days with continued BRJ supplementation. ${ }^{12}$ While more studies agree with these findings, ${ }^{22-25}$ not all agree. ${ }^{26}$ Interestingly, Christensen et $\mathrm{al}^{26}$ recently noted that in highly trained cyclists with an average $\mathrm{VO}_{2}$ max of $72 \pm 4 \mathrm{~mL} / \mathrm{kg} / \mathrm{min}$, consuming $0.5 \mathrm{~L}$ of BRJ had no effect on performance. This suggests that the impact of BRJ may be influenced by the training status of the individual consuming this product (see Table 1).

In nonathletic populations, the impact of BRJ may also have a positive influence. In fact, Kenjale et a ${ }^{27}$ studied patients with peripheral arterial disease to test whether BRJ would increase plasma nitrite and exercise tolerance and decrease muscle fractional $\mathrm{O}_{2}$ extraction. Eight participants consumed either $0.5 \mathrm{~L}$ of $\mathrm{BRJ}\left(18.1 \mathrm{mmol} / \mathrm{L} \mathrm{NO}_{3}^{-}\right)$ or an isocaloric placebo on two separate occasions, while performing an incremental, graded treadmill running test. The increased plasma nitrite following BRJ consumption was associated with increased exercise tolerance (walked $18 \%$ longer before claudication pain onset and experienced a $17 \%$ longer peak walking time) and decreased fractional $\mathrm{O}_{2}$ extraction. Thus, these findings support dietary $\mathrm{NO}_{3}^{-}$ ingestion, in the form of BRJ, increases nitrite-related $\mathrm{NO}$ signaling, resulting in enhanced peripheral tissue oxygenation in hypoxic areas and increased exercise tolerance in individuals with peripheral arterial disease. ${ }^{27}$ While it appears that BRJ supplementation may be useful for both athletes and nonathletes alike in order to improve aerobic exercise performance, the impact of BRJ on resistance exercise performance is not as clear. 


\section{$B R J$ and resistance exercise}

Extremely limited research has been conducted on the effects of BRJ and resistance exercise. ${ }^{11}$ In addition, only three studies to date have been published that investigate the use of betaine (a major BRJ constituent) on resistance exercise performance. ${ }^{6,28,29}$ The findings from these betaine studies are equivocal, with the overarching theme being a modest improvement in resistance exercise performance.

With specific regard to BRJ on resistance exercise performance, Bailey et $\mathrm{al}^{11}$ enlisted seven recreationally active males (age $28 \pm 7$ years) to consume either $0.5 \mathrm{~L} /$ day of BRJ ( $5.1 \mathrm{mmol} /$ day $\mathrm{NO}_{3}^{-}$) or a placebo (blackcurrant juice cordial with negligible $\mathrm{NO}_{3}{ }^{-}$content) for 6 days. During the last 3 days of supplementation, participants completed low and high (15\% and 30\% maximal voluntary isometric contractions, respectively) intensity "step" knee extension tests. Results indicated that BRJ more than doubled plasma nitrite concentrations and resulted in a $25 \%$ reduction in pulmonary $\mathrm{VO}_{2}$ from rest to low-intensity exercise. ${ }^{11}$ In addition, BRJ consumption resulted in a $36 \%$ reduction in the amount of phosphocreatine (PCr) degraded during low-intensity exercise (knee extensions) and a 59\% reduction during high-intensity exercise compared to placebo. ${ }^{11}$ These reductions in PCr usage were accompanied by a reduction in the total ATP utilization during both high and low-density exercise. However, the authors speculate that the reduced $\mathrm{O}_{2}$ cost may be due to an improved coupling between ATP hydrolysis and skeletal muscle force production rather than an increased mitochondrial phosphate $/ \mathrm{O}_{2}$ ratio ( $\mathrm{P} / \mathrm{O}$ ratio), which is the number of inorganic phosphate $(\mathrm{Pi})$ molecules used for ATP synthesis for every $\mathrm{O}_{2}$ consumed. ${ }^{11}$ Another intriguing finding of this study was a $25 \%$ increased time to task failure (knee extension exercise) in all seven participants that consumed BRJ. This may be a result of sparing $\mathrm{PCr}$ stores and reducing the $\mathrm{O}_{2}$ cost of exercise. ${ }^{11}$

\section{BRJ and hypoxic conditions}

Compelling research is highlighting the effectiveness of performing exercise under moderate hypoxic conditions to improve performance. ${ }^{30,31}$ To determine whether the dietary $\mathrm{NO}_{3}{ }^{-}$in $\mathrm{BRJ}$ would improve metabolism and oxidative function in muscle during hypoxic conditions, Vanhatalo et $\mathrm{al}^{32}$ performed a double-blind crossover study with nine healthy participants, moderately trained in recreational sport. The participants consumed either $0.75 \mathrm{~L}$ of BRJ $(9.3 \mathrm{mmol}$ $\left.\mathrm{NO}_{3}^{-}\right)$or a $\mathrm{NO}_{3}^{-}$-depleted placebo $\left(0.006 \mathrm{mmol} \mathrm{NO}_{3}^{-}\right)$before performing low $(28 \pm 2 \mathrm{~W})$ and high intensity $(48 \pm 4 \mathrm{~W})$ knee extension exercises to exhaustion. These exercises were performed under normoxic (control) and hypoxic $\left(14.45 \% \pm 0.05 \% \mathrm{O}_{2}\right)$ conditions, where the percentage of $\mathrm{O}_{2}$ was controlled by a filtration system. $\mathrm{BRJ}$ reduced hypoxic muscle metabolic "perturbation" (indicated by $\mathrm{PCr}$ degradation and Pi accumulation) during high-intensity exercise and returned exercise tolerance to normoxic conditions. In addition, BRJ eliminated the reduction in the PCr recovery rate with hypoxia. ${ }^{32}$ These findings suggest BRJ consumed under hypoxic conditions provides an additional performance stimulus to working muscle and allows participants to function as if in a normoxic environment. Practically, this research implicates that athletes may benefit from BRJ consumption when working at very high-intensities and/or at altitude by enhancing $\mathrm{O}_{2}$ utilization. Overall, the majority of the published research indicates a benefit for athletes from BRJ supplementation.

\section{Dosing of BRJ and dietary $\mathrm{NO}_{3}^{-}$}

It is important to note that the acute dose of $\mathrm{NO}_{3}^{-}$used in research studies ranges from $5.1 \mathrm{mmol}(0.32 \mathrm{~g})$ to $18.1 \mathrm{mmol}$ $(1.12 \mathrm{~g})$ which is four to 12 times greater than the typical daily dietary $\mathrm{NO}_{3}^{-}$intake in the United States. ${ }^{33}$

\section{Mechanisms of action for BRJ}

Several mechanisms have been postulated for the various exercise improvement effects of BRJ. A reduction in $\mathrm{PCr}$ degradation and the reduction of build-up of adenosine diphosphate (ADP) and Pi at the same relative exercise intensity following BRJ consumption ${ }^{7,12}$ are likely mechanisms responsible for the decrease in $\mathrm{O}_{2}$ cost (oxidative phosphorylation) of exercise and increased time to exercise failure (reduced muscle fatigue). Indeed, NO may lessen fatigue at the same exercise intensity due to a slowing of cross-bridge cycling kinetics by reducing calcium $\left(\mathrm{Ca}^{2+}\right)$ sensitivity by decreasing the number of cross bridges in the force generating state ${ }^{34}$ or by inhibiting the mechanical properties and adenosine triphosphatase activity of myofibrils. ${ }^{35} \mathrm{NO}$ also modulates ryanodine receptor $\left(\mathrm{Ca}^{2+}\right.$ release channels) activity by S-nitrosylation or oxidation of several classes of cysteine residues associated with the protein, thereby affecting $\mathrm{Ca}^{2+}$ release ${ }^{36}$ and inhibiting $\mathrm{Ca}^{2+}$-adenosine triphosphatase activity. ${ }^{37}$ Consequently, these data suggest that BRJ may have a regulatory influence on the ATP cost of force production. ${ }^{11}$

Larsen et a ${ }^{14}$ reported that muscle mitochondria extracted after $\mathrm{NO}_{3}{ }^{-}$supplementation indicated an improvement in oxidative phosphorylation efficiency ( $\mathrm{P} / \mathrm{O}$ ratio) and a decrease 
in state 4 respiration (basal respiration associated with maintenance costs). The improved mitochondrial $\mathrm{P} / \mathrm{O}$ ratio correlated with a reduction in $\mathrm{O}_{2}$ cost at rest and during exercise. These authors ${ }^{14}$ and others ${ }^{7,32}$ indicate that $\mathrm{NO}_{3}{ }^{-}$reduces the expression of ATP/ADP translocase, an enzyme involved in proton conductance. ${ }^{14} \mathrm{ATP} / \mathrm{ADP}$ translocase is a transporter protein that facilitates the mobilization of ATP and ADP into and out of the inner mitochondrial membrane for ATP use. ${ }^{38}$

Several proposed mechanisms for BRJ to enhance $\mathrm{PCr}$ / muscle recovery during hypoxia, such as that experienced during high-intensity exercise scenarios, include increased efficiency of mitochondria and increased delivery and perfusion of $\mathrm{O}_{2}$ to working muscles. ${ }^{32}$ Whether overall cellular metabolism is enhanced is yet to be determined. It is possible that gene expression regulation, mitochondrial biogenesis, immunomodulation, and cell cycle/apoptosis control also account for the ergogenic effects of BRJ.,39-41

\section{Antioxidant benefits}

While improvements in performance of both aerobic and anaerobic exercise are reported via numerous proposed mechanisms, the impact of BRJ serving as a potent dietary antioxidant must be explored. As such, the antioxidant capabilities of BRJ and its constituents could further enhance the ability to sustain exercise, or possibly, aid in recovery from exercise.

Intense exercise, especially to exhaustion, has been shown to increase free radical concentrations in the muscles and liver by two to three times. ${ }^{42}$ Interestingly, several recent investigations have examined the potential antiradical properties of certain constituents of BRJ, namely betacyanins and betaxanthins, the main pigments of red beetroots. ${ }^{3}$ In addition, Kanner et $\mathrm{al}^{4}$ reported that linoleate peroxidation by cytochrome c was inhibited by betanin from red beets. It was suggested that regular beetroot consumption may provide protection against certain oxidative stress-related disorders in humans, ${ }^{4}$ and therefore may serve as a useful strategy to enhance recovery from exercise and subsequent exercise performance.

\section{Conclusion}

Research examining the efficacy of BRJ as an exercise enhancer appears to support its use. Most studies have shown BRJ or its constituents to increase number of repetitions, power, and time to fatigue. ${ }^{7-12,27,43}$ However, while at least one of these performance improvements is typical, they are not all observed in each of these studies. $\mathrm{NO}_{3}{ }^{-}$from BRJ, working alone or synergistically with other components of
BRJ, has demonstrated a reduced $\mathrm{O}_{2}$ cost of exercise..$^{9-12,27}$ The primary mechanism of action for the efficacy of BRJ to improve performance appears to be related to muscle bioenergetics, specifically attenuating the decline in $\mathrm{PCr}$ concentrations, coupled with enhanced efficiency of oxidative phosphorylation. However, more research is required to fully elucidate all of the potential mechanisms. Of note for consumers, the effective dose yielding performance and health benefits in scientific research studies of dietary $\mathrm{NO}_{3}{ }^{-}$is approximately $1,500 \mathrm{mg} / \mathrm{L} \cdot{ }^{11,27}$ Nevertheless, BRJ appears to improve performance without any side effects, although more standardized research methods may be needed to clarify the above findings as well as potential contraindications of BRJ for endurance athletes (ie, potential hypotension concerns from over consumption of $\mathrm{NO}_{3}^{-}$). Interestingly, other constituents of BRJ, such as betalain, betaine, betanin, betacyanin, and betaxanthin, may offer additional performance ${ }^{44}$ and antioxidant health ${ }^{4}$ benefits, albeit via alternate mechanisms.

\section{Acknowledgments}

The authors would like to thank Amber Kinsey and Ann Frost for technical assistance in preparing this review article.

\section{Disclosure}

The authors report no conflicts of interest in this work.

\section{References}

1. Nutrition business journal's supplement business report. Nutrition Business Journal. 2010;3:29-56.

2. Betaine [webpage on the Internet]. Baltimore, MD: University of Maryland Medical Center; 2011 [updated May 7, 2013]. Available from: http://umm. edu/health/medical/altmed/supplement/betaine. Accessed: June 2013.

3. Escribano J, Pedreño MA, García-Carmona F, Muñoz R. Characterization of the antiradical activity of betalains from beta vulgaris L. roots. Phytochem Anal. 1998;9(3):124-127.

4. Kanner J, Harel S, Granit R. Betalains - a new class of dietary cationized antioxidants. J Agric Food Chem. 2001;49(11):5178-5185.

5. Detopoulou P, Panagiotakos DB, Antonopoulou S, Pitsavos C, Stefanadis C. Dietary choline and betaine intakes in relation to concentrations of inflammatory markers in healthy adults: the ATTICA study. Am J Clin Nutr. 2008;87(2):424-430.

6. Trepanowski JF, Farney TM, McCarthy CG, Schilling BK, Craig SA, Bloomer RJ. The effects of chronic betaine supplementation on exercise performance, skeletal muscle oxygen saturation and associated biochemical parameters in resistance trained men. J Strength Cond Res. 2011;25(12):3461-3471.

7. Lansley KE, Winyard PG, Bailey SJ, et al. Acute dietary nitrate supplementation improves cycling time trial performance. Med Sci Sports Exerc. 2011;43(6):1125-1131.

8. Murphy M, Eliot K, Heuertz RM, Weiss E. Whole beetroot consumption acutely improves running performance. J Acad Nutr Diet. 2012;112(4): $548-552$.

9. Lansley KE, Winyard PG, Fulford J, et al. Dietary nitrate supplementation reduces the $\mathrm{O} 2$ cost of walking and running: a placebo-controlled study. J Appl Physiol. 2011;110(3):591-600. 
10. Bailey SJ, Winyard P, Vanhatalo A, et al. Dietary nitrate supplementation reduces the $\mathrm{O} 2$ cost of low-intensity exercise and enhances tolerance to high-intensity exercise in humans. J Appl Physiol. 2009;107(4): 1144-1155.

11. Bailey SJ, Fulford J, Vanhatalo A, et al. Dietary nitrate supplementation enhances muscle contractile efficiency during knee-extensor exercise in humans. J Appl Physiol. 2010;109(1):135-148.

12. Vanhatalo A, Bailey SJ, Blackwell JR, et al. Acute and chronic effects of dietary nitrate supplementation on blood pressure and the physiological responses to moderate-intensity and incremental exercise. Am J Physiol Regul Integr Comp Physiol. 2010;299(4):R1121-R1131.

13. Hord NG, Tang Y, Bryan NS. Food sources of nitrates and nitrites: the physiologic context for potential health benefits. Am J Clin Nutr. 2009;90(1):1-10.

14. Larsen FJ, Schiffer TA, Borniquel S, et al. Dietary inorganic nitrate improves mitochondrial efficiency in humans. Cell Metab. 2011;13(2): 149-159.

15. Webb AJ, Patel N, Loukogeorgakis S, et al. Acute blood pressure lowering, vasoprotective, and antiplatelet properties of dietary nitrate via bioconversion to nitrite. Hypertension. 2008;51(3):784-790.

16. Maiorana A, O'Driscoll G, Taylor R, Green D. Exercise and the nitric oxide vasodilator system. Sports Med. 2003;33(14):1013-1035.

17. Hickner RC, Fisher JS, Ehsani AA, Kohrt WM. Role of nitric oxide in skeletal muscle blood flow at rest and during dynamic exercise in humans. Am J Physiol. 1997;273(1 Pt 2):H405-H410.

18. Gilligan DM, Panza JA, Kilcoyne CM, Waclawiw MA, Casino PR, Quyyumi AA. Contribution of endothelium-derived nitric oxide to exercise-induced vasodilation. Circulation. 1994;90(6):2853-2858.

19. Bradley SJ, Kingwell BA, McConell GK. Nitric oxide synthase inhibition reduces leg glucose uptake but not blood flow during dynamic exercise in humans. Diabetes. 1999;48(9):1815-1821.

20. Balon TW, Nadler JL. Evidence that nitric oxide increases glucose transport in skeletal muscle. J Appl Physiol. 1997;82(1):359-363.

21. Bloomer RJ. Nitric oxide supplements for sports. Strength Cond J. 2010;32:14-20.

22. Kelly J, Vanhatalo A, Wilkerson DP, Wylie LJ, Jones AM. Effects of nitrate on the power-duration relationship for severe-intensity exercise. Med Sci Sports Exerc. 2013;45(9):1798-1806.

23. Jones AM, Vanhatalo A, Bailey SJ. Influence of dietary nitrate supplementation on exercise tolerance and performance. Nestle Nutr Inst Workshop Ser. 2013;75:27-40.

24. Muggeridge DJ, Howe CC, Spendiff O, Pedlar C, James PE, Easton C. The effects of a single dose of concentrated beetroot juice on performance in trained flatwater kayakers. Int J Sport Nutr Exerc Metab. Epub April 9, 2013.

25. Wylie LJ, Kelly J, Bailey SJ, et al. Beetroot juice and exercise: pharmacodynamic and dose-response relationships. J Appl Physiol. 2013;115(3):325-336

26. Christensen PM, Nyberg M, Bangsbo J. Influence of nitrate supplementation on $\mathrm{VO}_{2}$ kinetics and endurance of elite cyclists. Scand J Med Sci Sports. 2013;23(1):e21-e31.

27. Kenjale AA, Ham KL, Stabler T, et al. Dietary nitrate supplementation enhances exercise performance in peripheral arterial disease. $J$ Appl Physiol. 2011;110(6):1582-1591.

28. Hoffman JR, Ratamess NA, Kang J, Gonzalez AM, Beller NA, Craig SA. Effect of 15 days of betaine ingestion on concentric and eccentric force outputs during isokinetic exercise. J Strength Cond Res. 2011;25(8):2235-2241.

29. Lee EC, Maresh CM, Kraemer WJ, et al. Ergogenic effects of betaine supplementation on strength and power performance. J Int Soc Sports Nutr. 2010;7:27.

30. Masschelein E, Van Thienen R, Wang X, Van Schepdael A, Thomis M, Hespel P. Dietary nitrate improves muscle but not cerebral oxygenation status during exercise in hypoxia. J Appl Physiol. 2012;113(5): $736-745$.
31. Wang JS, Wu MH, Mao TY, Fu TC, Hsu CC. Effects of normoxic and hypoxic exercise regimens on cardiac, muscular, and cerebral hemodynamics suppressed by severe hypoxia in humans. J Appl Physiol. 2010;109(1):219-229.

32. Vanhatalo A, Fulford J, Bailey SJ, Blackwell JR, Winyard PG, Jones AM. Dietary nitrate reduces muscle metabolic perturbation and improves exercise tolerance in hypoxia. J Physiol. 2011;589(Pt 22): 5517-5528.

33. Mensinga TT, Speijers GJ, Meulenbelt J. Health implications of exposure to environmental nitrogenous compounds. Toxicol Rev. 2003;22(1):41-51.

34. Heunks LM, Cody MJ, Geiger PC, Dekhuijzen PN, Sieck GC. Nitric oxide impairs $\mathrm{Ca} 2+$ activation and slows cross-bridge cycling kinetics in skeletal muscle. J Appl Physiol. 2001;91(5):2233-2239.

35. Galler S, Hilber K, Göbesberger A. Effects of nitric oxide on forcegenerating proteins of skeletal muscle. Pflugers Archiv. 1997;434(3): 242-245.

36. Hart JD, Dulhunty AF. Nitric oxide activates or inhibits skeletal muscle ryanodine receptors depending on its concentration, membrane potential and ligand binding. J Membr Biol. 2000;173(3):227-236.

37. Viner RI, Williams TD, Schöneich C. Nitric oxide-dependent modification of the sarcoplasmic reticulum Ca-ATPase: localization of cysteine target sites. Free Radic Biol Med. 2000;29(6):489-496.

38. Berg JM, Tymoczko JL, Stryer, L. Biochemistry. 6th ed. San Francisco, CA: WH Freeman; 2007.

39. Thomas DD, Liu X, Kantrow SP, Lancaster JR. The biological lifetime of nitric oxide: implications for the perivascular dynamics of $\mathrm{NO}$ and O2. Proc Natl Acad Sci U S A. 2001;98(1):355-360.

40. Hagen T, Taylor CT, Lam F, Moncada S. Redistribution of intracellular oxygen in hypoxia by nitric oxide: effect on HIF1alpha. Science. 2003;302(5652):1975-1978.

41. Victor VM, Nuñez C, D’Ocón P, Taylor CT, Esplugues JV, Moncada S. Regulation of oxygen distribution in tissues by endothelial nitric oxide. Circ Res. 2009;104(10):1178-1183.

42. Davies KJ, Quintanilha AT, Brooks GA, Packer L. Free radicals and tissue damage produced by exercise. Biochem Biophys Res Commun. 1982;107(4):1198-1205.

43. Hoon MW, Johnson NA, Chapman PG, Burke LB. The effect of nitrate supplementation on exercise performance in healthy individuals: a systematic review and meta-analysis. Int J Sport Nutr Exerc Metab. Epub April 9, 2013.

44. Pryor JL, Craig SA, Swensen T. Effect of betaine supplementation on cycling sprint performance. J Int Soc Sports Nutr. 2012;9(1):12.

45. Vanhatalo A, Fulford J, DiMenna FJ, Jones AM. Influence of hyperoxia on muscle metabolic responses and the power-duration relationship during severe-intensity exercise in humans: a 31P magnetic resonance spectroscopy study. Exp Physiol. 2010;95(4):528-540.

46. Cermak NM, Gibala MJ, van Loon LJ. Nitrate supplementation's improvement of 10-km time-trial performance in trained cyclists. Int $J$ Sport Nutr Exerc Metab. 2012;22(1):64-71.

47. Cermak NM, Res P, Stinkens R, Lundberg JO, Gibala MJ, van Loon LJC. No improvement in endurance performance after a single dose of beetroot juice. Int J Sport Nutr Exerc Metab. 2012;22(6): 470-478.

48. Bond H, Morton L, Braakhuis AJ. Dietary nitrate supplementation improves rowing performance in well-trained rowers. Int J Sport Nutr Exerc Metab. 2012;22(4):251-256.

49. Wilkerson DP, Hayward GM, Bailey SJ, Vanhatalo A, Blackwell JR, Jones AM. Influence of acute dietary nitrate supplementation on 50 mile time trial performance in well-trained cyclists. Eur J Appl Physiol. 2012;112(12):4127-4134

50. Muggeridge DJ, Howe CC, Spendiff O, Pedlar C, James PE, Easton C. A single dose of beetroot juice enhances cycling performance in simulated altitude. Med Sci Sports Exerc. Epub July 10, 2013. 
Nutrition and Dietary Supplements

Dovepress

\section{Publish your work in this journal}

Nutrition and Dietary Supplements is an international, peer-reviewed, open access journal focusing on research into nutritional requirements in health and disease, impact on metabolism and the identification and optimal use of dietary strategies and supplements necessary for normal growth and development. The journal welcomes papers covering original research, basic science, clinical \& epidemiological studies, reviews and evaluations, guidelines, expert opinion and commentary, case reports and extended reports. The manuscript management system is completely online and includes a very quick and fair peer-review system, which is all easy to use.

Submit your manuscript here: http://www.dovepress.com/nutrition-and-dietary-supplements-journal 